Recebido em 02/2013. Aceito para publicação em 05/2015.

\title{
AVALIAÇÃO MICROBIOLÓGICA DO SUCO DE LARANJA IN NATURA COMERCIALIZADO EM VIA PÚBLICA NA ZONA CENTRAL DE SÃO PAULO-SP
}

\section{MICROBIOLOGIC EVALUATION OF NATURAL ORANGE JUICE COMMERCIALIZED IN PUBLIC STREETS IN DOWNTOWN SÃO PAULO CITY, BRAZIL}

\author{
Daniel Ferreira Barros ${ }^{1}$ \\ Gabriella Sampaulo Martins Bento' \\ Laís Morais Nobre Scarance ${ }^{1}$ \\ Vanessa Diniz de Oliveira Andrade ${ }^{1}$ \\ Andrea Carvalheiro Guerra Matias ${ }^{2}$ \\ Edeli Simioni de Abreu²
}

Resumo: O objetivo deste estudo foi verificar a presença de microrganismos em amostras de sucos de laranja in natura coletados na zona central de São Paulo-SP e comparar com a legislação vigente. Foram coletadas três amostras de sucos de laranja in natura em diferentes pontos de venda. As análises foram realizadas para identificar a presença de mesófilos, fungos e coliformes, utilizando Ágar Triptona Soja (ATS), Batata Dextrose Ágar (BDA) e teste presuntivo e confirmativo para coliformes. Os valores encontrados estavam acima do recomendado para bolores, leveduras e bactérias. Quanto à presença de coliformes fecais, houve ausência em todas as amostras, e presença de $50 \%$ pelo teste presuntivo e $33,3 \%$ no teste confirmativo para coliformes totais. Ressalta-se a necessidade da adoção de boas práticas de manipulação de alimentos.

Palavras-chave: suco de laranja; qualidade; coliformes; microbiologia de alimentos.

Abstract: The aim of present study was to verify the presence of microorganisms in natural orange juice samples collected in downtown São Paulo city and compare them with the current legislation. Three samples were collected of natural orange juices from different places of sale. Analyzes were performed to identify the presence of mesophile, yeast, and coliforms, using Tryptone Soy Agar (TSA), Potato Dextrose Agar (PDA,) and presumptive and confirmative coliform tests. The values found were higher than recommended for mold, yeast, and bacteria. Fecal coliforms were not present in any samples, with the presence of 50\% for the presumptive test and $33.3 \%$ in the confirmative test for total coliforms. The results indicate the need to adopt best practices in food manipulation. Keywords: orange juice; quality; coliforms; food microbiology.

\footnotetext{
1 Graduando em Nutrição - Universidade Presbiteriana Mackenzie - UPM. E-mails: daniel.barros@mackenzie.br; gabisampaulo@hotmail.com; laisscarance@globo.com; vanessadoandrade@yahoo.com.br.

${ }^{2}$ Doutora em Saúde Pública - Universidade de São Paulo - USP. Docente do curso de Nutrição - UPM. E-mails: andrea.matias@mackenzie.br; edelisabreu@gmail.com.
} 


\section{INTRODUÇÃO}

A laranjeira (Citrus sinenses), dentre todas as árvores frutíferas, é a mais cultivada e pesquisada. A laranja foi disseminada pelo mundo, sofrendo mutações, originando novas variedades, com alterações no sabor, aroma, cor e tamanho (MATTE et al., 2006; ARRUDA et al., 2011).

A laranja caracteriza-se como uma das frutas de maior consumo em todo o mundo devido ao seu sabor, assim como por seu valor nutricional. Sendo fonte de vitamina $\mathrm{C} \mathrm{e}$ considerada um potente e efetivo antioxidante, mesmo se ingerida em pequenas quantidades. Além disso, seu consumo está relacionado com a prevenção de danos oxidativos e de determinadas enfermidades, como o escorbuto (FIGUEIREDO, 2009; DOLINSKY, 2011; SILVA et al., 2007).

O suco de laranja pode ser produzido industrialmente ou artesanalmente. O suco industrializado é pasteurizado a $90^{\circ} \mathrm{C}$, após esse processo são adicionados conservantes e corantes para não perder a sua cor original. A quantidade utilizada desses aditivos é padronizada para que o suco mantenha as suas características sensoriais da laranja in natura (RAIMUNDO et al., 2007; VIDOTTI, ROLLEMBERG, 2006).

Por sua vez, a produção do suco de laranja in natura é, geralmente, feita manualmente, com emprego de máquinas e utensílios sem a devida higienização. Nesse processo, o suco de laranja não é submetido a nenhum método de pasteurização e não há nenhum tipo de adição de conservantes, fazendo com que sua vida útil seja reduzida. Em grande parte das vezes, esse suco é comercializado em vias públicas, com armazenamento inadequado, podendo ser adquirido pelo consumidor com algum tipo de alteração física, química ou microbiológica (RUSCHEL et al., 2001; BRITO; ROSSI, 2005; MALLON; BORTOLZO, 2005; TRIBESS; TADINI, 2001).

A contaminação de sucos de laranja pode ser decorrente de más condições higiênicas, equipamentos sem a devida higienização, pelo ar e pela falta de preparo dos vendedores na manipulação correta de alimentos (RUSCHEL et al., 2001).

Os bolores presentes na superfície de frutas cítricas não são considerados patogênicos, não produzem odor e não interferem no sabor dos produtos sob condições adequadas de armazenamento e temperatura. Por sua vez, pode ocorrer desenvolvimento de bactérias lácticas, fungos e leveduras (MATTE et al., 2006; SHIGEOKA, 1999).

A análise microbiológica é a determinação qualitativa ou quantitativa de grupos de microrganismos, como, por exemplo, coliformes totais e fecais; enquanto uma está ligada a organismos patogênicos intestinais, a outra é considerada um indicador de contaminação fecal, respectivamente. O número de microrganismos pode aumentar, dependendo de fatores relacionados à conservação da fruta (NASCIMENTO; FURLANETTO, 1981). Nesse estudo, Nascimento e Furlanetto (1981) verificaram que em sucos produzidos com laranjas que apresentavam deterioração, a presença foi de 2500 vezes mais microrganismos do que em sucos produzidos com laranjas sem avarias. 
Segundo a Portaria n 410, de 27/09/74, do Ministério da Agricultura, em sucos in natura não congelados, deve haver ausência de microrganismos coliformes em 5 porções de $10 \mathrm{~mL}$ e ausência de microrganismos patogênicos (BRASIL, 1974).

Alguns microrganismos desenvolvem-se em ambientes de baixo $\mathrm{pH}$, como as bactérias ácido-láticas e as leveduras. É necessário que os sucos de laranja comercializados apresentem qualidade microbiológica e, para tanto, deve ser feita a correta higienização de equipamentos e superfícies de contato e de haver treinamento técnico para os manipuladores, sendo necessária, também, a fiscalização dos locais de vendas desses sucos (OLIVEIRA et al., 2006).

Nos últimos anos, a preocupação com a segurança alimentar vem crescendo. Os problemas de saúde pública acarretados por alimentos contaminados são de consenso geral, bem como a preocupação de se eliminar os microrganismos patológicos presentes nesses produtos. Contudo, grande parte dos estabelecimentos comerciais ambulantes não têm infraestrutura adequada, inexistindo a presença de instalações sanitárias e de abastecimento de água tratada, dificultando a correta higienização de alimentos e utensílios, aumentando o risco de transmissão de patógenos (NASCIMENTO; FURLANETTO, 1981; SALAY, 2004).

Considerando que o suco de laranja in natura é consumido por uma grande parte da população, tanto pela sua composição nutricional quanto por suas características físicas e sensoriais, e que sua qualidade microbiológica deve ser assegurada, o presente estudo objetivou verificar os microrganismos presentes no suco de laranja in natura comercializado no município de São Paulo e comparar os resultados encontrados com a legislação vigente.

\section{METODOLOGIA}

Foi realizado um estudo experimental de delineamento transversal, no qual foram avaliadas três amostras de suco de laranja in natura, coletadas de diferentes pontos de venda, em vias públicas, na zona central do município de São Paulo-SP.

As amostras foram coletadas no dia 02/04/2012 e transportadas a $10^{\circ} \mathrm{C}$ para 0 laboratório de microbiologia da Universidade Presbiteriana Mackenzie e, imediatamente, analisadas em duplicata.

Os testes realizados foram mesófilos, fungos e qualitativo de coliformes fecais e totais. Para tanto, foram pesados $25 \mathrm{~g}$ de cada suco em uma placa de Petri estéril. Em seguida, o suco foi homogeneizado com $225 \mathrm{~mL}$ de solução salina a $0,85 \%$, em um liquidificador previamente higienizado com álcool $70 \%$ e realizada a diluição seriada.

Para a contagem padrão de mesófilos aeróbios, foi inoculado $1 \mathrm{~mL}$ das diluições, por meio da utilização da técnica pour plate, utilizando-se Ágar Triptona Soja (ATS), indicada para o crescimento de bactérias aeróbias mesófilas. Para a verificação do crescimento de fungos aeróbios amostra, foi semeada em Batata Dextrose Ágar (BDA). As placas foram incubadas por $48 \mathrm{~h}$, entre $30^{\circ} \mathrm{C}$ e $35^{\circ} \mathrm{C}$, respectivamente. Após esse período, foi realizada a contagem 
de colônia se obtido as unidades formadoras de colônia por milímetro de produto (UFC/mL).

Foi realizado o teste qualitativo da presença de coliformes totais e fecais, utilizando a técnica dividida em teste presuntivo e confirmativo. Para a etapa do teste presuntivo, foram inoculados $10 \mathrm{~mL}$ da diluição $10^{-1}$, em tubo de ensaio contendo $10 \mathrm{~mL}$ de caldo LST (Lauril Sulfato Triptose), com tubos de Durhan invertidos, sendo, posteriormente, incubados a $35^{\circ} \mathrm{C}$ entre 24 e 48 horas. Após esse período, na ocorrência de turvação e formação de gás, foi realizado o teste confirmativo.

Para tanto, foram transferidas, com alça microbiológica estéril, 3 alçadas da amostra para tubos contendo caldo BVB (bile verde brilhante), incubados a $35^{\circ} \mathrm{C}$, por 24 a 48 horas, para a confirmação da presença de coliformes totais.

Para tubos positivos no teste confirmativo de coliformes totais, foram transferidas, com alça microbiológica estéril, 3 alçadas da amostra para tubos de Durhan invertido com caldo EC (Escherichia coli) e incubado a $44,5^{\circ} \mathrm{C}$, por 24 horas, para confirmação da presença de coliformes termotolerantes (coliformes fecais). As amostras com resultado positivo apresentaram turvação do meio, bem como a presença de gás do interior do tubo de Durhan.

Todas as análises foram realizadas em duplicata. Após, foram realizados controles negativos para os meios de cultura e para a solução salina utilizada para diluição das amostras.

Os dados foram tabulados com utilização do software Microsoft Excel $2010 \AA$ e comparados às recomendações da Resolução-RDC № 12, de 02/01/2001.

O presente estudo não foi submetido ao comitê de ética, visto que a pesquisa não envolve seres humanos ou animais, sendo mantido sigilo absoluto sobre os locais em que o material foi coletado.

\section{RESULTADOS E DISCUSSÃO}

Foram coletadas três amostras de sucos de laranja in natura comercializados em vias públicas, na zona central de São Paulo-SP. Ao medir a temperatura do produto, verificou-se que variou entre $12^{\circ} \mathrm{C}$ e $18^{\circ} \mathrm{C}$, diferentemente dos resultados encontrados por Brito e Rossi (2005), que apresentaram temperatura do suco entre $9,7^{\circ} \mathrm{C}$ e $10,3^{\circ} \mathrm{C}$, sendo que essa diferença pode ter ocorrido devido à maneira de transporte do produto ao laboratório, uma vez que a embalagem térmica utilizada pode não ter preservado a temperatura do produto. Porém, o transporte não ultrapassou 30 minutos, tempo seguro para não alterar os resultados.

Em seguida, foram realizados os testes para verificação da quantidade de bolores e fungos por UFC/mL e a presença de coliformes totais e fecais, por meio do teste presuntivo e confirmativo. Na Tabela 1, verifica-se a contagem de colônias de cada amostra, de acordo com o meio de cultura. 
Tabela 1 - Determinação de bolores e leveduras por UFC/mL, em amostras de sucos de laranja in natura, São Paulo, 2012

\begin{tabular}{ccc}
\hline \multirow{2}{*}{ Amostra } & \multicolumn{2}{c}{ Média de bolores e leveduras (UFC/mL) } \\
\cline { 2 - 3 } & PDA & TSA \\
\hline A & $5,9 \times 10^{6}$ & $5,5 \times 10^{5}$ \\
B & $2,5 \times 10^{3}$ & $1,3 \times 10^{3}$ \\
C & $2,5 \times 10^{3}$ & $1,2 \times 10^{3}$ \\
\hline
\end{tabular}

PDA - Potato Dextrose Agar ; TSA - Tryptone Soy Agar.

De acordo com a Resolução-RDC no 12/2001, o limite máximo tolerado de unidades formadoras de colônia é de $10^{2}$, sendo os valores encontrados acima do preconizado pela legislação. Os valores encontrados variam de $10^{3}$ a $10^{6}$, demostrando que o produto estaria inadequado para o consumo.

Em estudo desenvolvido por Arruda et al. (2009), que analisaram a eficácia da sanitização no processamento mínimo de laranja pera, verificou-se que a quantidade de bolores e leveduras encontrada foi de $4,0 \times 10^{2} \mathrm{UFC} / \mathrm{mL}$ e de bactérias foi de $4,0 \times 10^{2} \mathrm{UFC} / \mathrm{mL}$, o que difere do presente estudo, em que foram encontrados $5,9 \times 10^{6} \mathrm{UFC} / \mathrm{mL}$ e $2,5 \times 10^{3}$ $\mathrm{UFC} / \mathrm{mL}$ de bolores e leveduras e de $1,2 \times 10^{3} \mathrm{UFC} / \mathrm{mL}$ a $5,5 \times 10^{5} \mathrm{UFC} / \mathrm{mL}$ de bactérias.

$\mathrm{Na}$ Tabela 2, pode-se verificar a determinação de coliformes fecais e totais.

Tabela 2 - Determinação da presença ou ausência de coliformes totais e fecais em amostras de sucos de laranja in natura, São Paulo, 2012

\begin{tabular}{cccc}
\hline Amostra & $\begin{array}{c}\text { Coliformes totais } \\
\text { (Teste presuntivo) }\end{array}$ & $\begin{array}{c}\text { Coliformes totais } \\
\text { (Teste confirmativo) }\end{array}$ & Coliformes fecais \\
\hline A1 & Ausência & Ausência & Ausência \\
A2 & Ausência & Ausência & Ausência \\
B1 & Presença & Ausência & Ausência \\
B2 & Ausência & Ausência & Ausência \\
C1 & Presença & Presença & Ausência \\
C2 & Presença & Presença & Ausência \\
\hline
\end{tabular}

Em relação aos coliformes totais e fecais, pode-se verificar que houve ausência de coliformes fecais para todas as amostras estudadas. Já, em um estudo realizado por Ruschel et al. (2001), no qual foram analisadas 52 amostras de sucos de laranja in natura, foi constatado que, aproximadamente, $6 \%$ das amostras encontravam-se inadequadas para 0 consumo quanto aos coliformes fecais. E, no estudo de Brito e Rossi (2005), aproximadamente $7 \%$ das amostras também se apresentavam irregulares para o consumo, utilizando-se a quantidade de coliformes fecais como referência. 
Foram identificados coliformes totais em $50 \%$ das amostras (B1, C1 e C2) para o teste presuntivo e em 33,3\% para o teste confirmativo (amostras $\mathrm{C} 1$ e C2). Ao serem analisadas amostras de suco de laranja comercializadas em cinco estabelecimentos, Brito e Rossi (2005) identificaram que em todos eles houve a presença de coliformes totais nos sucos analisados.

Os coliformes fecais e totais são de poluição fecal, o que demonstra a falta de boas práticas na manipulação do suco de laranja. Esses microrganismos, embora não causem nenhuma enfermidade, podem ser indicadores da presença de outros microrganismos patogênicos.

\section{CONCLUSÃO}

As análises realizadas nos sucos de laranja in natura apresentaram resultado positivo para os testes presuntivos de coliformes totais nas amostras $B$ e $C$, sendo que no teste confirmativo, apenas a amostra $C$ foi positiva; a amostra $A$ foi negativa em ambos os testes realizados. A presença de coliformes fecais não foi confirmada em nenhuma amostra analisada. Todas as amostras apresentaram resultados para mesófilos e fungos em números acima do permitido pela Resolução-RDC nº 12/2001.

A presença de coliformes totais em amostras de suco in natura, embora não indique um risco potencial ao consumidor, demonstra a necessidade de implementação e monitoramento de boas práticas em locais onde se manipulem esses alimentos.

\section{REFERÊNCIAS BIBLIOGRÁFICAS}

ARRUDA, M. C. de. et al. Eficácia da sanificação no processamento mínimo de laranja 'Pêra'. Ciênc. agrotec., Lavras, v. 33, n. spe, p. 1866-1870, 2009. Disponível em: $\quad<$ http://www.scielo.br/scielo.php?script=sci arttext\&pid=S141370542009000700028\&lng=en\&nrm=iso $>$. Acesso em : 17 jun. 2015.

ARRUDA, M. C. et al. Atmosfera modificada em laranja 'pera' minimamente processada. Bragantia, Campinas, v. 70, n. 3, p. 664-671, 2011.

BRASIL. Ministério da Agricultura. Portaria $n^{\circ} 410$, de 27 de setembro de 1974. Diário Oficial da União, Brasília, DF, 08 out. 1974.

Agência Nacional de Vigilância Sanitária. Resolução-RDC n 12, de 02 de janeiro de 2001. Aprova o Regulamento Técnico sobre padrões microbiológicos para alimentos. Diário Oficial da União, Brasília, DF, 10 jan. 2001.

BRITO, C. S.; ROSSI, D. A. Bolores e leveduras, coliformes totais e fecais em sucos de laranja in natura e industrializados não pasteurizados comercializados na cidade de Uberlândia-MG.

Biosci. J., Uberlândia, v. 21, n. 1, p. 133-140, 2005.

DOLINSKY, M. Recomendações Nutricionais e Prevenção de Doenças. Rio de Janeiro: 
Roca, 2011. 160p.

FIGUEIREDO, P. P. Condições higiênico-sanitárias no preparo de suco de laranja in natura em lanchonetes comerciais em Goiânia, GO. Rev. Ciênc. Saúde, São Paulo, v. 27, n. 4, p. 574-375, 2009.

MALLON, C.; BORTOLOZO, E. A. F. Q. Alimentos comercializados por ambulantes: uma questão de segurança alimentar. Ci. Biol. Saúde, Ponta Grossa, v. 10, n. 3/4, p. 65-76, 2004.

MATTE, C. R. et al. Avaliação microbiológica de sucos de laranja in natura não pasteurizados durante a 16‥ Fenasoja no município de Santa Rosa/RS. In: CONGRESSO BRASILEIRO DE CIÊNCIA E TECNOLOGIA DE ALIMENTOS, 20., 2006, Curitiba. Anais... alimentos e agroindústrias no contexto internacional. Curitiba: sbCTA-PR, 2006.

NASCIMENTO, D.; FURLANETTO, S. M. P. Determinação quantitativa de grupos de bactérias em sucos de laranja ao natural. Rev. Saúde Pública, São Paulo, v. 15, n. 2, p. 221-235, 1981.

OLIVEIRA, J. C. et al. Características microbiológicas do suco de laranja in natura. Ciênc. Tecnol. Aliment, Campinas, v. 26, n. 2, p. 241-245, 2006.

RAIMUNDO, E. et al. Cor, viscosidade e bactérias lácticas em suco de laranja pasteurizado e submetido ao efeito a luz durante o armazenamento. Alim. Nutr., Araraquara, v. 18, n. 4, p. 449-456, 2007.

RUSCHEL, C. K. et al. Qualidade microbiológica e físico química de sucos de laranja comercializados nas vias públicas de Porto Alegre/RS. Ciênc. Tecnol. Aliment., Campinas, v. 21, n. 1, p. 94-97, 2001.

SALAY, E. Consumo alimentar fora do domicílio: implicações para pesquisas em segurança alimentar e nutricional. Rev. Saúde Pública, São Paulo, v. 14, n. 8, p. 78-89, 2004.

SHIGEOKA, D. S. Tratamento Térmico Mínimo do Suco de Laranja Natural: Estudo da Viabilidade de Armazenamento em Latas de Alumínio. 1999. 55p. Dissertação (Mestrado em Engenharia) - Escola Politécnica, Universidade de São Paulo, São Paulo, 1999.

SILVA, P. T. et al. Estabilidades química, físico-química e microbiológica de suco de laranja cv. "pera" submetido a diferentes condições de estocagem. Bol. Centro Pesqui. Process. Aliment, Curitiba, v. 25, n. 2, p. 235-246, 2007.

TRIBESS, T. B.; TADINI, C. C. Suco de laranja natural minimamente processado: uma alternativa para ampliar o mercado de suco de laranja no Brasil. In: CONGRESSO INTERNACIONAL DE ECONOMIA E GESTÃO DE NEGÓCIOS NETWORKS EM AGROINDÚSTRIAS, 3., 2001, Ribeirão Preto. Anais... Ribeirão Preto: Edusp, 2001. v. 1. p. 159.

VIDOTTI, E. C.; ROLLEMBERG, M. C. E. Espectrofotometria derivativa: uma estratégia simples para a determinação simultânea de corantes em alimentos. Quím. Nova, São Paulo, v. 29, n. 3, p. 230-233, 2006. 